\title{
Oralidad y escritura en el corpus lírico de Horacio
}

\author{
ALFREDO EDUARDO FRASCHINI \\ Universidad de Buenos Aires
}

\begin{abstract}
RESUMO: O presente trabalho propõe uma incursão pelos traços específicos de oralidade e pelos procedimentos pontuais de escrita nas Odes e Epodos de Horácio. Uma vez estabelecidos os conceitos de oralidade e de escrita, com os quais se realiza a referida incursão, passase ao exame das principais estratégias do autor em ambos os campos: vocativos, marcas de primeira e segunda pessoas do discurso, interrogações, exortações e atitudes combinadas, jogos de exemplos e apótegmas, para a oralidade; linhas temáticas condutoras (particularmente o tempo) e jogo de oposições como procedimento unificador, para a escrita. Como aspecto essencial e fator de unidade estética, a música, apenas deduzivel a partir da métrica, mas presente na palavra e no verso. As conclusões apontam para o estreito vínculo que, com fins expressivos, se estabelece entre tais estratégias.
\end{abstract}

PALAVRAS-CHAVE: Estratégias; vocativos; exortações; interrogações; tempo; oposições.

Quod si me lyricis vatibus inseres, sublimi feriam sidera vertice ${ }^{1}$

(Hor., Carmina, I, 1, 35-36).

\section{Introducción}

La filología parece haber agotado, a lo largo de los últimos siglos, las posibilidades de análisis técnico del corpus horaciano, pese a lo cual, cada día - como solo ocurre con los textos fundacionales de cada cultura - ese corpus ofrece las posibilidades de una nueva aproximación, de un inusual ingreso, de un no transitado perfil de lectura.

Nuestra propuesta de hoy es un rastreo - sobre la totalidad de las composiciones líricas de Horacio, esto es, de las Odas y los Epodos - de componentes esenciales de oralidad y de escritura, tendiente a establecer el papel que una y otra juegan en la integración estética e ideológica del poemario.

Delimitaré en primer lugar cuáles son los criterios de oralidad y de escritura aplicables a este caso particular, para desarrollar luego, por lo menos esquemáticamente, la lectura propuesta. 


\section{Oralidad}

La poesía lírica monódica supone un proceso de comunicación profunda y de amplio espectro significativo entre el autor y un auditorio particularmente dispuesto a recibir un mensaje de índole personal y subjetivo, una trasmisión de ideas, sentimientos y opiniones, que son distintos de los hechos y descripciones concretos de la poesía épica, por ejemplo. El poeta es el yo que pone en su canto algo que surge totalmente de sí, de su realidad interior aunque sus referentes sean, con gran frecuencia externos -; el oyente (o lector) es el tú que responde a aquel canto con su silencio o su reflexión. La materia comunicativa es el cantomelodía, palabra y ritmo - que con su riqueza expresiva logra movilizar y comprometer al oyente en su relación con el emisor.

Para que ese proceso se optimice, el poeta acude a estrategias de acercamiento e integración con su alocutario, como la marcación fuerte de la primera y sobre todo la segunda persona, reforzada con los vocativos, las alternancias de exempla y apotegmata, las interrogaciones retóricas y las exhortaciones dirigidas precisamente a esa segunda persona.

El objetivo es la generación de un clima comunicativo en el que predomine la interacción afectiva del poeta y el oyente.

\section{Escritura}

El proceso de composición del poema supone una tarea escritural planificada - minuciosamente, en el caso de Horacio -, la puesta en marcha de otras estrategias que permitan abrir el campo de la interpretación y enriquecer sus matices significativos. Esta labor apunta al encarrilamiento racional del mensaje subjetivo en el clima de interacción afectiva que la oralidad va creando.

Los objetivos del proceso escritural horaciano son fundamentalmente dos. El primero, de tipo estrictamente literario, es la conformación de un modelo estético. Su corpus lírico es la muestra viva de un arte poética mucho más valiosa que todas las normas, consejos y opiniones vertidos por el poeta en las Sátiras y las Epístolas, incluida la de los Pisones. El otro, de carácter metaliterario, es la conformación de una muestra de ideario filosófico y político, particularmente del epicureísmo y el estoicismo, y de una adhesión formalmente incondicional al principado de Augusto.

A lo largo del poemario hay una línea temática conductora, el tiempo, y un procedimiento unificador, el juego de oposiciones.

La estrecha correlación entre la oralidad y la escritura en el transcurso lírico engendra un proceso de configuración progresiva del corpus lírico que se enriquece en cada nueva lectura.

\section{Las estrategias de la oralidad}

La mención del "otro" por medio de nombres propios, verbos y pronombres; la presencia virtual del "otro" a través de la pregunta directa, la exhortación o la combinación de actitudes que lo involucran; la trasposición intencionada de género, mediante la "dramatización" de un pasaje; y la recurrencia a los modelos de sabiduría popular, son 
algunos de los recursos con los que Horacio da vigor dialogístico y vivacidad de comunicación con ese "otro", receptor, inmediato o a la distancia, de su mensaje poético.

\subsection{Vocativos}

La casi totalidad de las Odas y los Epodos tienen un destinatario explícito, que se presenta como interlocutor privilegiado de Horacio. Amigos - como Mecenas, Virgilio, Tibulo, y no pocos desconocidos -, mujeres que tuvieron alguna relación afectiva con el poeta o que representan a un tipo particular (vieja, bruja, prostituta) - como Pirra, Lidia, Lyde, Canidia, Cinara -, dioses, deidades, coperos, jóvenes y muchachas en general, y el grueso de sus lectores en algunos casos, encarnan a ese vocativo que define al vínculo entre emisor y destinatario del canto, y no se confunde con una mera nominación exclamativa.

Esos vocativos aparecen a menudo amplificados y enriquecidos con elementos afectivos y didácticos - recurso eminentemente escritural - como para señalar los caracteres del vínculo al lector poco avisado:

Maecenas atavis edite regibus,

o et praesidium et dulce decus meum ${ }^{2}$ (Od. I, 1, 1-2);

I...../ Maecenas, mearum

grande decus columenque rerum ${ }^{3}(\mathrm{Od}$. II, 17, 3-4);

Docte (sc. Maecenas) sermones utriusque linguae 4 (Od. III, 8, 5);

Mercuri, facunde nepos Atlantis, qui feros cultus hominum recentum voce formasti catus et decorae

more palaestrae,

te canam, magni Iovis et deorum

nuntium curvaeque lyrae parentem, callidum quidquid placuit iocoso

condere furto ${ }^{5}$ (Od. I, 10, 1-8);

O diva, gratum quae regis Antium,

praesens vel imo tollere de gradu mortale corpus vel superbos

vertere funeribus triumphos ${ }^{6}(\mathrm{Od} . \mathrm{I}, 35,1-4)$;

O saepe mecum tempus in ultimum

deducte Bruto militiae duce

/... I 


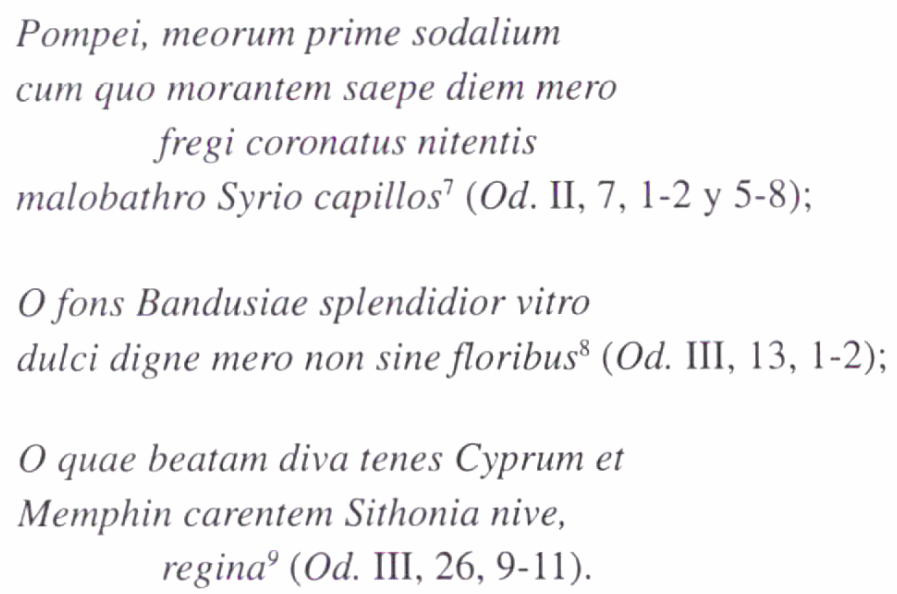

El más extenso de los vocativos, cuya intención didáctica para con el oyente-lector resulta, a partir de esa extensión, más destacada, es el de Apolo en el libro IV de las Odas:
Dive, quem proles Niobea magnae
vindicem linguae Tityosque raptor
sensit et Troiae prope victor altae
Phthius Achilles,
ceteris maior, tibi miles impar,
filius quamvis Thetidis marinae
Dardanas turris quateret tremenda
cuspide pugnax.
$/ \ldots /$
Doctor argutae fidicen Thaliae,
Phoebe, qui Xantho lavis amne crines,
Dauniae defende decus Camenae,
levis Agyeu ${ }^{10}$ (Od. IV, 6, 1-8, 25-28).

\subsection{Las personas del discurso}

Las marcas de la primera y de la segunda persona se subrayan con los verbos y sobre todo con los pronombres, como en $\mathrm{Od}$. I, 20, breve composición en la que los rasgos de oralidad se perfilan nítidamente a través de una suerte de invitación que el poeta hace a su amigo Mecenas:

Vile potabis modicis Sabinum cantharis, Graeca quod ego ipse testa

conditum levi, datus in theatro cum tibi plausus, 


\author{
care Maecenas, eques, ut paterni \\ fluminis ripae simul et iocosa \\ redderet laudes tibi Vaticani \\ montis imago. \\ Caecubum et prelo domitam Caleno \\ tu bibes uvam: mea nec Falernae \\ temperant vites neque Formiani \\ pocula colles $^{11}$ (Od. I, 20).
}

En $O d$. I, 34, el tono declarativo de los primeros versos supone una autosemblanza con la que se presenta ante sus lectores para desarrollar luego su reflexión sobre las mutaciones de la Fortuna:

\author{
Parcus deorum cultor et infrequens \\ insanientis dum sapientiae \\ consultus erro, nunc retrorsum \\ vela dare atque iterare cursus \\ cogor relictos $^{12}($ Od. I, 34, 1-5).
}

\title{
3.3. Interrogaciones y exhortaciones
}

Las interrogaciones retóricas dirigidas a la segunda persona crean un clima de diálogo con respuestas elididas, como en $O d$. I, 8, donde catorce de sus dieciséis versos constituyen un desarrollo de ese tipo de interrogaciones; o en $O d$. I, 12, donde el sujeto de la interrogación pasa de la segunda persona a la tercera, y finalmente a la primera; o en $O d$. II, 12, donde la interrogación final se convierte en una poética implícita, mediante una gran metáfora sobre lo que corresponde expresar en cada género literario; o en $\mathrm{Od}$. I, 29, composición estructurada en su totalidad como una serie de cuatro interrogaciones tras el vocativo:

$$
\begin{aligned}
& \text { Icci beatis nunc Arabum invides } \\
& \text { gazis, et acrem militiam paras } \\
& \text { non ante devictis Sabaeae } \\
& \text { regibus, horribilique Medo } \\
& \text { noctis catenas? quae tibi virginum } \\
& \text { sponso necato barbara serviet? } \\
& \text { puer quis ex aula capillis } \\
& \text { ad cyathum statuentur unctis, } \\
& \text { doctus sagittas tendere Sericas } \\
& \text { arcu paterno? quis neget arduis } \\
& \text { pronos relabi posse rivos } \\
& \text { montibus et Tiberim reverti, }
\end{aligned}
$$




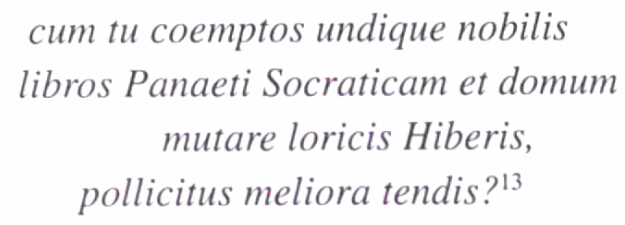

Rasgos más claramente de oralidad muestran las exhortaciones, como las que hace a Taliarco, en $O d$. I, 9, para que eche leños al fuego y sirva vino con el ánfora sabina, para que deje en manos de los dioses aquello que no puede hacer él por sí mismo, para que no pregunte por lo que ocurrirá en el futuro ni desprecie los dulces amores ni las danzas mientras sea joven; o en $O d$. I, 11, donde recomienda a Leuconoe ser prudente, filtrar los vinos, no abrigar largas speranzas para tiempos breves, y principalmente gozar del día presente sin confiar en el de mañana; o en el final de $O d$. I, 16, donde la exhortación adquiere particular intensidad a través del contraste con una clara marcación pronominal de la primera persona:

nunc ego mitibus

mutare quaero tristia, dum mihi

fias recantatis amica

opprobriis anumimque reddas ${ }^{14}(\mathrm{Od}$. I, 16, 25-28).

Casos similares se observan en $O d$. II, 9; III, 10; III, 17; III, 29; y en el Epodo XIII:

Tu vina Torquato move consule pressa meo

cetera mitte loqui / [...]/

illic omne malum vino cantuque levato,

deformis agrimoniae dulcibus alloquiis ${ }^{15}$ (Ep. XIII, 6-7 y 17-18).

\subsection{Combinaciones de actitudes}

Un interesante período hipotético con apódosis exhortativa aparece en los versos iniciales de $O d$. II, 3:

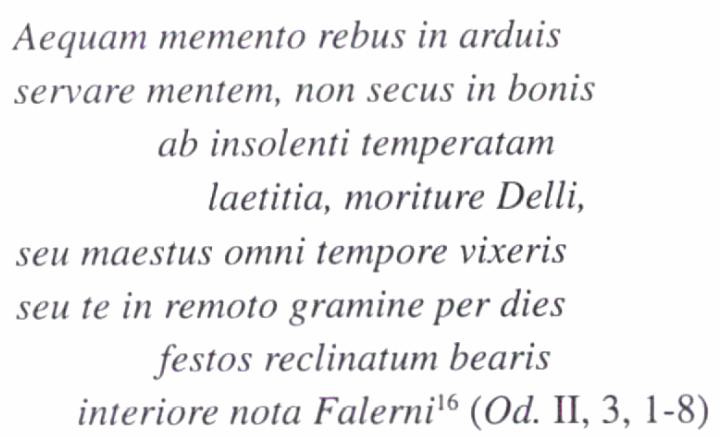

En $O d$. IV, 1 se produce una curiosa combinación interrogativa-exhortativa en los dos primeros versos, dirigidos a Venus: 


\author{
Intermissa, Venus, diu \\ rursus bella moves? Parce precor, precor ${ }^{17}$.
}

Y como contrapartida, otra interrogativa-enunciativa con cambio de alocutario, en este caso, un ser humano presumiblemente muy bello, en los últimos:

Sed cur heu, Ligurine, cur

manat rara meas lacrima per genas?

Cur facunda parum decoro

inter verba cadit lingua silentio?

Nocturnis ego somniis

iam captum teneo, iam volucrem sequor

te per gramina Martii

campi, te per aquas, dure, volubilis ${ }^{18}$ (Od. IV, 1, 33-40).

Combinaciones actitudinales de otros tipos aparecen en $O d$. II, 5 y Ep. VI, en ambos casos, sin vocativo expreso. En el primero, enunciaciones y exhortaciones :

\author{
/ ... / tolle cupidinem \\ immitis uvae: iam tibi lividos \\ distinguet Autumnus racemos \\ purpureo varius colore ${ }^{19}$ (Od. II, 5, 9-12).
}

En el otro, interrogaciones, un enunciado y una exhortación:
Quid immerentis hospites vexas canis ignavus adversum lupos?
Quin huc inanis, si potes, vertis minas, et me remorsum petis? / [...]
tu cum timenda voce complesti nemus, proiectum odoraris cibum.

Cave, cave: namque in malos asperrimus

parata tollo cornua ${ }^{20}$ (Ep. VI, 1-4 y 9-12).

\title{
3.5. Recursos teatrales
}

Tres composiciones del corpus reproducen escenas que podrían asimilarse a un género dramático - monólogo o diálogo explícito o sobreentendido. Allí la oralidad está muy tamizada por la escritura, sobre todo en $O d$. III, 9, el canto amebeo de dos amantes, prolijamente estructurado con criterio paralelístico de construcción y de léxico.

En Od. I, 15, el monólogo de Nereo dirigido a Paris supone oídos sordos del alocutario; en cambio en $O d$. I, 27, es el poeta mismo quien invita a uno de sus amigos a hacer públicas sus confidencias amorosas, a lo que el joven parece no estar dispuesto: 


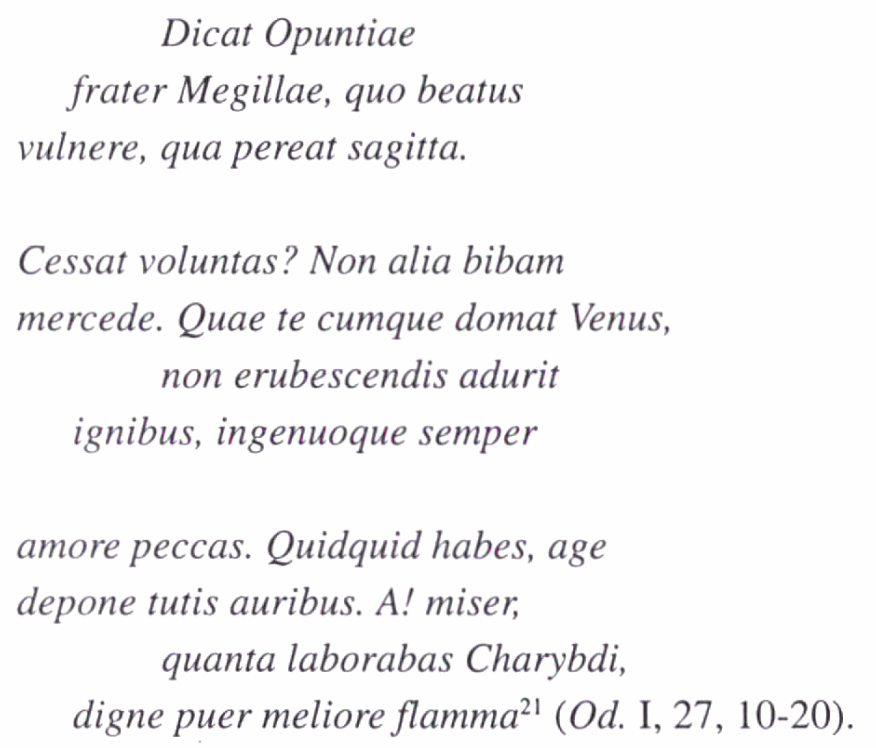

\subsection{Huellas de la tradición oral}

Para concluir este panorama de estrategias de la oralidad, recordemos los juegos de "apophthegmata" y "exempla" que guardan ecos claros de la sabiduría popular y del sentido común. Ellos se ven cuidadosamente enlazados en $O d$. II, 10, donde la primera y la última estrofas, dirigidas a su amigo Licinio, son apotegmas ilustrados con imágenes marinas, de tono moralizante:

Rectius vives, Licini, neque altum semper urgendo neque, dum procellas cautus horrescis, nimium premendo litus iniquum. /... /

Rebus angustis animosus atque fortis appare; sapienter idem contrahes vento nimium secundo turgida vela ${ }^{22}$ (Od. II, 10, 1-4 y 21-24).

El "pensamiento central" - versos 13-15 - es otro apotegma:

Sperat infestis, metuit secundis alteram sortem bene praeparatum pectus ${ }^{23}$ (Od. II, 10, 13-15).

Los ejemplos aparecen en las imágenes del pino, la torre y los montes (versos 9-12), en el nivel terrenal; y en las de Júpiter y Apolo (versos 15-20), en el mítico. El concepto rector del poema, la "aurea mediocritas", se enlaza en una suerte de combinación de apotegma y ejemplo en la segunda estrofa: 


\section{Auream quisquis mediocritatem \\ diligit, tutus caret obsoleti \\ sordibus tecti, caret invidenda}

sobrius aula ${ }^{24}(O d$. II, 10, 5-8).

En Od. II, 3, el mismo juego se da en dimensiones más amplias: el apotegma inicial ocupa dos estrofas y otras dos, el final; el ejemplo está enmarcado por las estrofas antedichas; y en I, 22, al apotegma inicial de dos estrofas sigue un ejemplo de otras dos, para finalizar con una exhortación a una segunda persona no claramente identificable.

\section{Las estrategias de la escritura}

Quedaron mencionados al comienzo algunos de los objetivos literarios y metaliterarios del corpus horaciano, y no sería este el lugar adecuado para extendernos sobre ellos. En cambio sí es importante detenernos en lo que llamamos la línea temática conductora y en el procedimiento unificador del corpus, y que conforman, en gran medida, las principales estrategias discursivas en el campo estrictamente escriturario.

\subsection{El tiempo, línea temática conductora}

La crítica moralizante de Horacio apunta generalmente al mal uso que los hombres hacen de su tiempo existencial. Ambición, avaricia, audacia y desenfreno, son algunas causas sobresalientes de ese mal uso cuyo efecto más lamentable es que los hombres no vivan intensa y profundamente, no aprehendan su tiempo en la justa medida, sino que apenas transcurran un rápido y estéril camino hacia la muerte y el olvido.

Poéticamente, el tiempo aparece con tres caracteres bien diferenciados en el corpus lírico horaciano : como protagonista, como marco existencial y como eje vital.

En el primero de ellos, es dable observar una rica gama de denominaciones concretas del tiempo, de cualidades que se le atribuyen y de acciones que le son propias; y al lado de ellas, un cúmulo de denominaciones alegóricas, fundamentalmente vinculadas con la Naturaleza - y en forma particular con las estaciones del año - y con la vida y la muerte de los seres humanos.

La palabra "tempus" es casi un tabú para el poeta, de ahí que sea la denominación más infrecuente y con escasos matices significativos: tiempo propiamente y cuantitativamente dicho, época o vida, momento o circunstancia. "Aevum" es el tiempo propiamente dicho, limitado o eterno; es una época, edad o generación; es la vida:

\section{Quid brevi fortes iaculamur aevo multa? ${ }^{25}$ (Od. II, 16, 17-18).}

Similares matices semánticos tienen "aetas", "dies", "annus"; y algo más restringidos, "saeculum" y "hora". "Nox" es el tiempo inactivo, el olvido y la eternidad; "hiems" es la unidad de tiempo y la época desfavorable; y luego, con valor semántico más acotado, "spatium" y "via leti", por vida, y "luna" por período temporal. 
Horacio califica al tiempo con adjetivos que indican casi exclusivamente fugacidad, brevedad, fatalidad, y los caracteres negativos resultantes de esas cualidades; y lo pone como sujeto de acciones que tienden al movimiento, el escape, la fuga, la destrucción y el quite y la eventual restitución de las cosas.

Tomado como eje existencial, el tiempo juega en Horacio un papel conductor en la crítica hacia quienes lo malgastan y viven como juguetes de las fuerzas externas hasta que la muerte aparece y concluye el juego.

Varios son los motivos de esta particular situación, y el primero es la acumulación de bienes materiales en detrimento de los espirituales, como se ve en $O d$. I, 3, 25-28 y 37-40); en $O d$. II, 16, 42-44; en $O d$. II, 18, 1-11 y 17-22); y en $O d$. II, 2, 1-8. Allí el poeta desarrolla la idea de que ambición, avaricia, inclinación al lujo y los placeres fáciles, y la creencia en burdas supersticiones provocan en el hombre un estado de alienación aguda. El segundo motivo es la preocupación por el futuro. Horacio recomienda no averiguar lo que ha de ocurrir, en $O d$. I, 9 y I, 11; y no exagerar las prevenciones para el futuro, ya que, aun cuando se hagan de buena fe, irán a parar inevitablemente a manos de herederos que no siempre son merecedores de tales afanes, como puede leerse en $O d$. II, 3 y II, 14. El tercer motivo es la no aceptación de la condición propia de cada uno. La natural inestabilidad del hombre le hace creer que todo cambio le procura un mejoramiento. Cuando no acierta con el cambio adecuado, y ello es frecuente, intenta otros, en los que pierde su tiempo y sus posibilidades de ser feliz. La ambición de bienes materiales y la no aceptación de su estado actúan como polos de un movimiento sin fin, convirtiéndose sucesivamente en causa y efecto de un instable y constante fluir.

Frente al cuadro de los errores existenciales del hombre en el empleo de su tiempo, Horacio presenta la necesidad de lograr un "buen vivir" mediante el aprovechamiento integral del tiempo y el goce intenso de la vida sobre una base ética. Aquí el tiempo se constituye en eje vital, como se ve en $O d$. I, 9; I, 11; y II, 3. Para lograr el estado que esa idea del "buen vivir" preconiza, existen caminos que corren en dirección opuesta a la de aquellas actitudes humanas que motivan el malgasto del tiempo y la frustración existencial del hombre: la sencillez y sobriedad de costumbres - Od. II, 16; I, 38; III, 24; II, 11; II, 16; Epodo II -, la búsqueda de equilibrio, la "aurea mediocritas" - Od. II, 10; II, 3; II, 11; I, 7; III, 21 -; el ejercicio de virtudes - Od. III, 6; III, 2; III, 5; III, 24 - y el cultivo de las bellas artes - Od. I, 1; II, 20; III, 30; IV, 8; IV, 9.

El "carpere diem" que sintetiza metafóricamente todo el pensamiento horaciano con respecto al tiempo, significa básicamente aprovechar en grado máximo cada instante de la vida, rescatar los valores positivos del pasado y eliminar la preocupación por el futuro.

\subsection{El juego de oposiciones, procedimiento unificador}

Una lectura panorámica del corpus lírico horaciano advierte sobre el empleo constante de contrastes en la definición de objetos, imágenes o escenas, o en la caracterización particular de personas, situaciones o circunstancias. Esta definición por opuestos posee matices de intensidad según la combinación de recursos que el poeta pone en movimiento 
en cada poema y actúa en planos cuantitativos - oposición de poemas, de pasajes, de palabras -, semánticos - personas del discurso, tiempos y espacios - y de nivel expresivo, según se trate de oposiciones fuertes o débiles, directas o encubiertas. Ese juego, reiterado en todas sus variantes a lo largo del poemario, resulta ser un procedimiento metódicamente aplicado por el poeta como recurso primero de su intención expresiva y por ende, unificador de su batería discursiva.

\subsubsection{La oposición "poema a poema"}

David Porter (1975) ha visto en el libro IV de las Odas una agrupación temáticamente contrastante de los poemas: seis de ellos - 1, 7, 10, 11, 12 y 13 - tienen como eje significativo la acción del tiempo sobre los seres humanos; otros cinco - 2, 3, 6, 8, y 9 - se centran en la acción de la poesía como factor de inmortalización; un tercer núcleo temático se filtra en las odas 2 y 9 : la celebración de Augusto y su régimen. En el primer grupo cobran particular vigencia los vínculos entre tiempo y amor, tiempo y belleza, tiempo y sensualidad, tiempo y olvido, tiempo y flores, que pueden resumirse en la díada "tiempo-vida // tiempomuerte".

Una de las composiciones del primer grupo, la IV, 7 , forma pareja, por el tratamiento del tema de la primavera frente a la fugacidad de la vida, con la I, 4. Tomando a ambas como una sola expresión poética, encontramos su opuesto en I, 9, donde se canta al invierno y a los goces de la vida que esa estación facilita, distintos de aquellos que se dan en primavera. El juego de oposiciones resulta, así, doble, ya que cada composición lleva su juego propio: primavera y muerte (I, 4 y IV, 7), e invierno y vida (I, 9). En las tres composiciones se da el fenómeno que Moritz (1968) llama "central thought", una frase que por un lado resume la idea principal del texto y por otro actúa - en la mitad del poema - como "bisagra" entre las secciones en oposición:

\section{Pallida Mors aequo pulsat pede pauperum tabernas regumque turris ${ }^{26}$ (I, 4, 13-14);}

Quid sit futurum cras fuge quaerer ${ }^{27}$ (I, 9, 13);

Damna tamen celeres reparant calestia lunae ${ }^{28}$ (IV, 7, 13).

Otro caso de oposición "poema a poema" es el de la oda I, 3, dedicada a su amigo Virgilio, que se va de viaje, y el epodo X, que alude al viaje de su enemigo Mevio. El propémptico es un augurio de buen viaje que, en el caso de la oda citada, se combina con una reflexión sobre los peligros del mar y la audacia del hombre que los aborda, con altos riesgos, en un acto de desmesura que esconde una incontrolable ambición. Si el augurio es de tono contrario - es decir, que en lugar de desear un viaje favorable se manifiestan deseos de tempestades y naufragios, como ocurre en el epodo $\mathrm{X}$ - puede hablarse de un anti-propémptico, que da la clave de oposición entre ambos poemas. Esa clave se enriquece con otra oposición, la del largo excursus sobre el mar y sus peligros (Od. I, 3, 9-40) al que Horacio da valor universal, con el breve "paradeigma" de Pallas y Ayax (Ep. X, 11-14) aplicado a nivel personal. 


\subsubsection{La oposición "sección a sección"}

Son numerosos los poemas de Horacio que presentan una división bipartita de características significativas contrastantes. En algunos casos hay una tercera parte que actúa como polo equilibrante y delimitador de las que se oponen.

Un caso particular, el de la oda III, 9, a la que ya hemos aludido con referencia a la oralidad "teatral", presenta las dos secciones regularmente fragmentadas en oposiciones parciales. La estructuración contrastante se produce en grupos de dos dísticos, los impares, puestos en boca de un varón - que podría ser el poeta mismo -, y los pares, en boca de una mujer, Lydia. Cada par de estrofas consecutivas se inicia con una palabra clave : "donec" (vv. 1 y 5); "me" (vv. 9 y 13); "quid" (v. 17); y "quamquam" (v. 21).

Del mismo modo, cada final de grupo actúa como clave conclusiva :

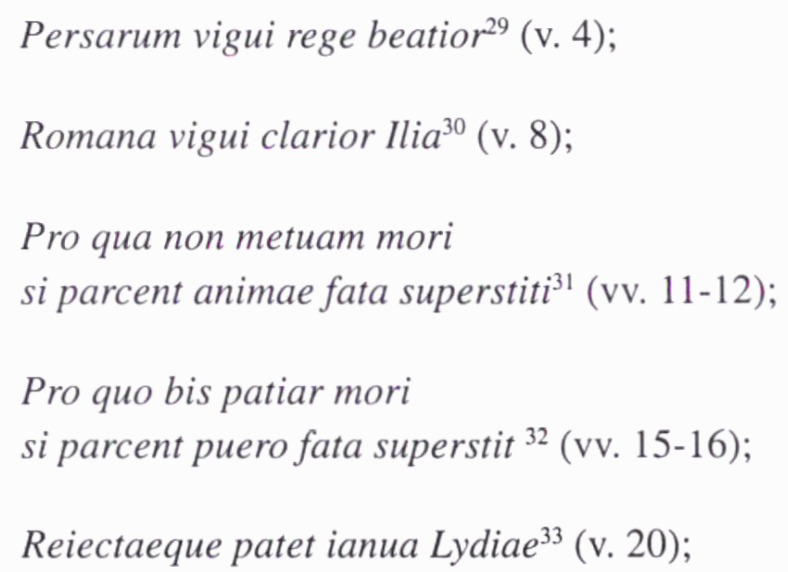

Tecum vivere amem, tecum obeam libens $^{34}$ (v. 24).

En la oda II, 10, distintos críticos han visto estructuras opositivas distintas. Toll (1955) propone un esquema bipartito: en la primera sección (vv. 1-8), una advertencia iluminada con un juego opositivo, y un enunciado ilustrado con otra oposición; en la segunda (vv. 924), se distinguen tres tramos: una advertencia vehiculizada en el ejemplo de los árboles y las torres, una nota de esperanza reforzada con otras oposiciones y una reiteración de la imagen marítima inicial. Collinge, citado por Reagan (1970), en cambio, se inclina por una división en dos exactas mitades: en la primera se presentan dos temas - "urgendo" y "premendo" - que se ilustran con imágenes; en la segunda se desarrolla una nueva idea - "sperat infestis / metuit secundis" - y se vuelve a la imagen náutica inicial. Christopher Reagan (1970) propone una sucesión de pasajes contrastantes de acción e inacción, de ejemplos y apotegmas; en este esquema hay dos puntos culminantes signados por la intensidad semántica de los adjetivos : "celsae graviore" (v. 9) y "angustis animosus" (v. 21).

\subsubsection{Otros tipos de oposiciones}

Una aproximación más menuda al texto horaciano nos advierte sobre el empleo de oposiciones de menor extensión aunque no de menor intensidad. Así pueden verse pasajes, 
esto es, oraciones que no alcanzan a formar una sección del poema, de significación opuesta - vida / muerte, primavera / invierno, sueño / vigilia, guerra / paz, virtud / vicio, amor / indiferencia - en $O d$. I, 5; I, 22; I, 25; I, 28; II, 14; II, 18; III, 15; IV, 8, por citar algunos ejemplos notables. Del mismo modo, y en nivel de palabra, es abundante el juego de oposición conceptual - feliz / desdichado, agricultor / navegante, campo / ciudad, jóvenes / viejos; público / privado - en numerosísimas composiciones. Otros casos puntuales, como el contraste entre "ego" y "alii" o entre el pasado y el presente, merecerían un detalle que no entra en esta comunicación, pero que pueden hallarse comentados en la bibliografía citada.

Podrían llenarse largas y numerosas páginas con observaciones y ejemplos de este procedimiento escritural básico (convergencia temática y juego de oposiciones) que el corpus lírico horaciano manifiesta. En el caso presente, basta con lo dicho para mostrar cómo la escritura del poeta resulta claramente planificada y técnicamente resuelta, más allá de las variantes temáticas (que en definitiva convergen en un punto) y de los constantes rasgos de oralidad que enriquecen su expresión lírica.

\section{La palabra y la música}

Uno de los motivos fundamentales de su fama postrera será, según el mismo Horacio, el haber sido el primero en trasladar el "carmen Aeolium" a los "modos Italicos" (Od. III, 30), esto es, reproducir en lengua latina las cadencias rítmicas - y eventualmente melódicas o armónicas - de la poesía lírica griega. Si bien varios años antes Catulo había logrado valiosas trasposiciones de los metros eólicos, el epíteto "primus" con el que Horacio se autocalifica resulta acertado si se considera el sentido poético profundo de dicha traslación.

Horacio sistematiza el empleo de los ritmos y las combinaciones estróficas adecuándolos a los contenidos líricos, filosóficos, religiosos, políticos, amistosos, burlescos o eróticos, de cada poema. Así, la estrofa alcaica le sirve para cantar el pasado glorioso de Roma o para advertirle a Póstumo la fugacidad del tiempo; la estrofa sáfica, para que los coros juveniles celebren el jubileo augustal o para recomendarle a Licinio el equilibrio y la sensatez; el verso asclepiadeo menor, para dedicar su obra a Mecenas o para afirmar la persistencia de la misma más allá de la muerte física del poeta; y los juguetones yambos para aguzar las saetas de su crítica social.

El carácter eminentemente musical de la lírica horaciana - resultante del trasvasamiento de las formas de la lírica monódica griega - se patentiza en la mención de los instrumentos típicos que acompañan al canto - lyra, fides, barbitos - en pasajes estrechamente vinculados con su condición de poeta, como el final de $O d$. I, 1 y el de $O d$. II, 16. Aun cuando de esa música apenas pueda atisbarse hoy el ritmo, imaginar lejanamente la melodía y ni siquiera suponer una estructura armónica, el lector avisado intuye que en el corpus horaciano ella es el vehículo más ajustado a su mensaje. Significante y significado poéticos constituyen de ese modo un modelo en acción.

Tal vez sea este el punto en que oralidad y escritura convergen y donde una y otra el canto y la técnica poética, la fuerza sonora de la palabra y su intención significativa - se articulen con mayor exactitud y densidad expresiva. 


\section{Palabras finales}

La ideología horaciana, de raíz epicúrea y cuño alejandrino, se reviste de romanidad en sus composiciones líricas a través de la búsqueda incesante de un equilibrio que dé sentido trascendente a la vida y a la poesía. Aprovechar el día, mantener el espíritu ecuánime, elegir la dorada medianía, vivir contento con poco y feliz lejos de las preocupaciones, buscar el ocio, compartir la alegría con los amigos, lograr en el vino y en el amor el olvido del dolor y de la inmenencia de la muerte: he aquí un puñado de ideas que el poeta desarrolla y reitera a través del canto, en un diálogo casi íntimo con el lector, que, junto a él o a dos mil años de distancia, sigue disfrutándolo.

Música e idea, diálogo interactivo, técnica depurada al servicio de la riqueza expresiva, fusión exquisita de oralidad y escritura, son rasgos del corpus lírico horaciano que alimentan su vigencia y lo hacen indestructible a las lluvias, los vientos y la innumerable serie de los años.

\section{Notas}

1 - "Pues si tú me incluyes entre los poetas líricos, tocaré los astros con mi cabeza".

2 - "Mecenas, nacido de antiguos reyes, oh protección y dulce honor mío".

3 - "Mecenas, gran honor y sostén de mis cosas".

4 - (Mecenas), "conocedor de discursos en una y otra lengua".

5 - "Mercurio, elocuente nieto de Atlas, que, sabio, los feroces hábitos de los hombres recién creados transformaste con la palabra y la práctica de la honrosa palestra, a ti te cantaré, mensajero del gran Júpiter y de los dioses y creador de la cóncava lira, y hábil para lograr cualquier cosa que te agrada con hurto furtivo".

6- "Oh, diosa que riges el agradable Ancio, capaz de elevar a un cuerpo mortal de su más baja condición o de convertir a los soberbios triunfos en cortejos fúnebres".

7 - "Oh tú, llevado a menudo conmigo al borde la muerte siendo Bruto jefe del ejército [...] Pompeyo, el primero de mis amigos, con quien frecuentemente abrevié el lento día con vino, ceñidos mis cabellos brillantes con el malabatro sirio".

8 - "Oh, fuente de Bandusia más diáfana que un cristal, digna de un dulce vino, no sin flores".

9 - "Oh diosa que gobiernas a la feliz Chipre y a Menfis, libre de nieve sitonia, oh reina".

10 - "Oh dios a quien, como vengador, padecieron la prole de Niobe de orgullosa lengua y el raptor Ticio y el Ftío Aquiles, casi vencedor de la alta Troya, más grande que los demás pero incomparable a ti como guerrero, aun cuando como hijo de la marina Tetis golpeara obstinado las torres Dardanias con su tremenda lanza [...] Citarista maestro de la armoniosa Talía, Febo, que mojas tus cabellos con la corriente del Janto, defiende el honor de la Camena Daunia, oh delicado Agyeo".

11 - "Beberás un Sabino sencillo en modestos cántaros, que yo mismo sellé guardado en ánfora griega cuando te fue dada en el teatro una ovación, querido Mecenas, caballero, cuando las riberas del río patrio y la agradable imagen del monte Vaticano te devolvían conjuntamente las alabanzas. Tú beberás el Cécubo y la uva prensada en un trapiche caleno; a mis copas no las alegran ni las vides Falernas ni las colinas de Formio".

12 - "Yo, parco cultor y poco asiduo de los dioses mientras vago sin rumbo confiado en un conocimiento insensato, ahora me veo obligado a tender las velas en sentido contrario y a recorrer caminos ya transitados". 
13 - "Iccio, ¿ahora envidias los magníficos tesoros de los Árabes y preparas un violento ejército contra los reyes de Saba, nunca antes vencidos, y forjas cadenas para el Medo aterrador? ¿Cuál de las esclavas bárbaras te servirá habiendo sido muerto su prometido? ¿Cuál muchacho del palacio, experto en arrojar flechas séricas con el arco paterno será destinado a servir las copas con sus cabellos perfumados? ¿Quién negará que los rápidos arroyos pueden volver hacia los montes y revertir el curso del Tíber, cuando tú, habiendo prometido cosas mejores, pretendes cambiar los libros del noble Panecio, que se compran en todos lados, y la escuela socrática, por las corazas ibéricas?"

14 - "Ahora yo quiero transformar las cosas tristes en agradables, mientras te conviertas en mi amiga y, depuestas mis ofensas, me devuelvas el ánimo".

15 - "Tú saca los vinos exprimidos durante el consulado de mi Torcuato (i.e. el año de mi nacimiento) y omite mencionar las restantes cosas [...] Allí alivia todo mal con vino y con canto, dulces consuelos de la deforme melancolía".

16 - "Acuérdate de mantener el espíritu ecuánime en las circunstancias difíciles y no menos en las favorables, alejado de una alegría insólita, mortal Delio, ya sea que hayas vivido triste todo el tiempo, ya te hayas regodeado durante los días festivos, recostado en la escondida gramilla, con un Falerno de antigua etiqueta".

17 - "Oh, Venus, de nuevo provocas guerras hace tiempo interrumpidas. Abstente, te ruego, te ruego".

18 - "Pero ¿por qué, ay, Ligurino, por qué se desliza una rara lágrima por mis mejillas? ¿Por qué mi lengua elocuente se detiene entre las palabras con un silencio poco decoroso? En mis sueños nocturnos a veces te tengo atrapado, otras, te persigo como a un ave por los pastos del Campo de Marte y, oh, insensible, por las aguas arremolinadas".

19 - "Deja de lado el gusto de la uva ácida: ya el variado otoño pintará de color purpúreo los morados racimos".

20 - “¿Por qué, perro cobarde frente a los lobos, atacas a los extraños que no lo merecen? ¿Por qué, si puedes, lanzas amenazas inútiles y me buscas a mí, dispuesto a devolver tu mordisco? Tú, cada vez que llenas el bosque con tu temible voz, olfateas el alimento arrojado. Cuídate, cuídate, porque muy feroz levanto mis cuernos preparados contra los malvados".

21 - "Que el hermano de la Opuncia Megilla diga con qué herida, con qué flecha muere feliz. ¿No tienes ganas? No beberé por otro precio. Cualquiera sea la Venus que te domina, te quema con fuegos no vergonzosos y siempre te equivocas por un amor honesto. Deposita en oídos seguros cualquier cosa que tengas, vamos. Ah, desdichado, por cuán enorme Caribdis sufrías, oh, muchacho digno de mejor llama".

22 - "Vivirás más rectamente, Licinio, no buscando siempre la alta mar ni, mientras precavido te horrorizas de las tormentas, apretando demasiado la orilla peligrosa. (... ) Muéstrate animoso y fuerte en las circunstancias angustiosas; igualmente con sabiduría recogerás las velas hinchadas por un viento demasiado favorable".

23 - "Un pecho bien preparado espera la otra suerte en las circunstancias difíciles y la teme en las favorables".

24 - "Cualquiera que elige la dorada medianía carece, seguro, de las suciedades de una casa deteriorada; carece, sobrio, de un palacio envidiable".

25 - ¿Por qué nos lanzamos, fuertes, hacia muchas cosas en un tiermpo breve?"

26 - "La pálida muerte golpea con pie justo las casuchas de los pobres y las torres de los reyes".

27 - "Evita averiguar lo que ocurrirá mañana".

28 - "Sin embargo las rápidas lunas reparan los daños celestes".

29 - "Me sentí fuerte más feliz que el rey de los Persas".

30 - "Me sentí fuerte, más famosa que la Ilia Romana".

31 - "Por la cual no temería morir si los hados favorecen al alma sobreviviente". 
32 - "Por el cual aceptaría morir dos veces si los hados favorecen al muchacho sobreviviente".

33 - "La puerte se abre a la rechazada Lidia".

34 -"Querría vivir contigo, contigo moriría de buen grado".

\title{
Referencias bibliográficas
}

CARRUBBA, R. The structure of Horace, Odes, I 3: a propempticon for Virgil. American Journal of Philology CV 2, 1984, 166-173.

DE WITT, N. Epicurean doctrine in Horace. Classical Philology XXXIV 2, 1939, 127-134.

ELDER, J. Horace, C. I,3. American Journal of Philology LXXIII, 1952, 140-158.

FRASCHINI, A. El juego de oposiciones como procedimiento de base en la escritura horaciana. Anales de Filología Clásica XIV, 1996, 98-148.

. El tiempo: punto de convergencia de la temática horaciana. Anales de Filología Clásica XI, 1986, 63-100.

. El vino de Horacio. Letras XI-XII, 1984-1985, 68-89.

MORITZ, L. Some "central" thoughts on Horace, Odes. Classical Quarterly XVIII, 1968, 116-131.

PEROZIM, J. Tempo e espaço em Horacio. Stylos 30, 1980, 1-22.

PORTER, D. The recurrent motifs of Horace, Carmina IV. Harvard Studies in Classical Philology LXXIX, 1975, 189-228.

REAGAN, C. Horace, Carmen II 10: the use of oxymoron as a thematic statement. Rivista di Studi Classici XVIII 2, 1970, 177-185.

TOLL, H. Unity in the Odes of Horace. Phoenix 9, 1955, 160 ss.

FRASCHINI, Alfredo Eduardo. Oral speech and writing in Horace's lyric corpus. Classica. São Paulo, 13/14, p. 351-366, 2000/2001.

\begin{abstract}
This paper proposes a general view of specific characteristics of oral speech and writing special ways in horace Odes and Epodi. Once the concepts of oral speech and writing by which that general view is done have been established, the work goes through the research of the principal strategies of the Latin poet in both aspects. Vocatives, marks of the first and second persons of the speech, interrogatives, exhortations and combined actitudes, links between "exempla" and "apophthegmata"; all these points taking into account the oral speech forms. Conducting thematic lines (particulary time) and remarked opposite points as unifying writing process. As an essential frame and sthetic unity element, the music, quite suggested by different rhytms and metrics, is present in words and verses. The conclusions are referred to the narrow links between those strategies with expressive objectives.
\end{abstract}

KEYWORDS: Strategies; vocatives; exhortations; interrogatives; time; oppositions. 